\title{
COMUNICAÇÃO
}

\section{PARÂMETROS CINÉTICOS DE LINHAGENS DE LEVEDURA ISOLADAS DE ALAMBIQUES MINEIROS}

\author{
Kinetic parameters of yeasts strains isolated from cachaça distilleries in Minas Gerais/Brazil
}

\author{
Cibele Tosin Stroppa ${ }^{1}$, José Guilherme Lembi Ferreira Alves ${ }^{2}$, \\ Ana Luíza França de Figueiredo ${ }^{3}$, Cristina Calabresi Castro ${ }^{3}$
}

\begin{abstract}
RESUMO
Foram isoladas leveduras prevalescentes de dois alambiques, em Betim e Rio Manso/MG, por meio de plaqueamento (WLN) e caracterizadas segundo a macromorfologia de colônias, após 8 dias de incubação a $32^{\circ} \mathrm{C}$. A amostra de Rio Manso apresentou 4 linhagens dominantes, com concentrações entre 2,0 x $10^{7} \mathrm{e} 4,0 \times 10^{5} \mathrm{UFC} / \mathrm{mL}$. No alambique de Betim foram isoladas três linhagens dominantes, com contagens entre $1,3 \times 10^{8} \mathrm{e} 2,0 \times 10^{4} \mathrm{UFC} / \mathrm{mL}$. Foram determinados a velocidade específica máxima de crescimento ( $\mu \max )$ e o fator de conversão de substrato em biomassa (Yx/s) para dois isolados. Os valores de $\mu$ max foram 0,24 e $0,4 \mathrm{~h}^{-1}$, sendo que a linhagem RM01 apresentou maior valor. Para Yx/s, os resultados obtidos pelas linhagens RM01 e CV01 foram 0,179 e 0,185 g. $\mathrm{g}^{-1}$, respectivamente. Verificou-se uma semelhança nos resultados entre as linhagens RM01 e CV01. Concluiu-se que, do ponto de vista de $\mu$ max e de Yx/s, a melhor linhagem para produção de cachaça é a RM01.
\end{abstract}

Termos para indexação: Cachaça, levedura fermentadora, rendimento em biomassa, velocidade de crescimento.

\begin{abstract}
Predominant yeasts of two cachaça distilleries were isolated in the cities of Betim and Rio Manso, in the State of Minas Gerais and characterized using WLN agar, according to colony morphology, after 8 days of imcubation at $32^{\circ} \mathrm{C}$. The sample from Rio Manso presented 4 dominant yeasts with concentrations between $2.0 \times 10^{7}$ and $4.0 \times 10^{5} \mathrm{CFU} / \mathrm{mL}$. At Betim distillery, three dominant yeasts were isolated with cell density between $1.3 \times 10^{8}$ and $2.0 \times 10^{4} \mathrm{CFU} / \mathrm{mL}$. The values of the maximum specific velocity for growth $(\mu \max )$ and the conversion factor for substrate into cells $(\mathrm{Yx} / \mathrm{s})$ were determined for two isolates. The $\mu \mathrm{max}$ values were 0.24 and $0.4 \mathrm{~h}^{-1}$, being RM01 strain the one with the highest value. Regarding to $\mathrm{Yx} / \mathrm{s}$, the results obtained by strains RM01 and CV01 were 0.179 and $0.185 \mathrm{~g} . \mathrm{g}^{-1}$, respectively. Resemblances of results were observed between strains RM01 and CV01. It was concluded that, as far as $\mu \max$ and $\mathrm{Yx} / \mathrm{s}$ are concerned, the best strain to produce cachaça is RM01.
\end{abstract}

Index terms: Cachaça, yeast, cell yield, growth velocity.

\section{(Recebido em 18 de maio de 2006 e aprovado em 9 de novembro de 2007)}

Em Minas, atualmente, existem cerca de 8.000 fábricas de aguardente, disseminadas por todas as regiões. Com uma produção média de 150 litros por dia, essas fábricas têm como principais características a fermentação natural, sem ingredientes químicos, e a destilação em alambiques simples, num único estágio. A aguardente produzida, de boa qualidade, mesmo comercializada a preços superiores, tem vencido a concorrência com o produto industrializado. A tradição da prática artesanal encontra-se amplamente difundida no Estado, com o produtor controlando todas as etapas de fabricação, desde a seleção da variedade de cana até o envelhecimento do produto (RIBEIRO, 2002). A padronização da qualidade tem sido um problema para a profissionalização do setor. Cada safra é única e até dentro de uma mesma safra são freqüentes as variações de sabor e/ou composição.

A falta de controle da microbiota responsável pela fermentação é um dos fatores que levam às variações organolépticas entre as safras. Entre as leveduras envolvidas no processo fermentativo, a Saccharomyces cerevisiae é a predominante, sendo responsável pela maior parcela da fermentação (PATARO et al., 2000; SCHWAN \& CASTRO, 2001). Além das leveduras, podem aparecer bactérias contaminantes provenientes da cana-de-açúcar

\footnotetext{
'Bióloga, Doutora em Tecnologia de Alimentos - Departamento de Ciências Exatas e Tecnologia/DCET - Cetro Universitário de Belo Horizonte/Uni-BH Avenida Professor Mário Werneck, 1685 - 30455-610 - Belo Horizonte, MG - cibelestroppa@yahoo.com.br

Engenheiro Químico - Departamento de Ciência dos Alimentos/DCA - Universidade Federal de Lavras/UFLA - Cx. P. 3037 - $37200-000$ - Lavras, MG jlembi@ufla.br

${ }^{3}$ Engenheira de Alimentos - Departamento de Ciências Exatas e Tecnologia/DCET - Cetro Universitário de Belo Horizonte/Uni-BH - Avenida Professor Mário Werneck, 1685 -30455-610 - Belo Horizonte, MG - aluiza_ff@yahoo.com.br; criscalabresi@yahoo.com.br
} 
e água utilizadas no processo (CLETO et al., 2009). A seleção de linhagens iniciadoras que apresentam tolerância às variações ocorridas durante o processo fermentativo, é uma alternativa para garantir uma alta produtividade e a manutenção da qualidade do produto (PATARO et al., 2002). Outra vantagem é o início mais rápido do processo, evitando-se os riscos de contaminação apresentados pela fermentação espontânea, com menor competição por nutrientes essenciais, maior rendimento, qualidade e padronização da bebida produzida (FLEET et al., 1984; QUEROL et al., 1992; SANNI \& LONNER, 1993).

As culturas iniciadoras dominam o processo, porque são adicionadas em altas concentrações, prevalecendo sobre a microbiota selvagem. Mesmo assim, a flora transitória tem uma participação importante no processo (BARROS-LOPES et al., 1996). Estas linhagens mostram uma maior adaptação ao meio e às condições particulares de fermentação, além de formação de compostos que determinam a produção de bebidas típicas da região (LONGO et al., 1992).

Fermentações em pequena escala são conduzidas para distinguir a levedura inoculada de outras suspeitas de serem contaminantes. Métodos de caracterização de leveduras através de determinações de seu desempenho fermentativo têm sido utilizados na produção de etanol carburante e cachaça (ANDRIETTA et al., 1995, 1999; OLIVEIRA et al., 2004; STROPPA et al., 2000).

Neste trabalho, objetivou-se o isolamento de linhagens de levedura de fábricas artesanais de cachaça da região de Belo Horizonte/MG e sua caracterização com base nas características morfológicas das colônias e em alguns parâmetros cinéticos (velocidade específica máxima de crescimento - $\mu$ máx e fator de conversão de substrato em biomassa - Yx/s) como procedimento para seleção de leveduras iniciadoras.

\section{Isolamento e caracterização das linhagens de levedura}

Foram coletadas amostras de vinho em dois alambiques artesanais de duas localidades da região de Belo Horizonte: Betim (dorna em início e dorna em fase final de fermentação); Rio Manso (dorna em fase final da fermentação). As amostras foram plaqueadas na superfície de WLN Agar adicionado de 100 ppm de ampicilina e incubadas a $32^{\circ} \mathrm{C}$, por 8 dias.

As leveduras foram caracterizadas pelo perfil macromorfológico das colônias (tamanho, borda, superfície, relevo e padrão de cores). Foram isoladas todas as colônias diferentes que apresentaram contagens de, no máximo, 2 ciclos logarítmicos abaixo da contagem do tipo mais populoso.

As linhagens foram avaliadas através de suas curvas de crescimento e foram determinadas as suas velocidades específicas máximas de crescimento ( $\mu$ max) e seus fatores de conversão de substrato em biomassa $(\mathrm{Yx} / \mathrm{s})$.

\section{Pré-inóculo}

Os microrganismos foram repicados em tubos de ensaio com $10 \mathrm{~mL}$ de meio complexo, esterilizado $\left(121^{\circ} \mathrm{C} / 15\right.$ $\mathrm{min}$ ), contendo $470 \mathrm{~mL} / \mathrm{L}$ de caldo de cana-de-açúcar (Saccharum sp.), da variedade SP 813250, a 190 Brix; $1 \mathrm{~g} / \mathrm{L}$ de cloreto de potássio; $4 \mathrm{~g} / \mathrm{L}$ de extrato de levedura; $4 \mathrm{~g} / \mathrm{L}$ de fosfato monobásico de potássio; $1 \mathrm{~g} / \mathrm{L}$ de cloreto de amônia e $0,6 \mathrm{~g} / \mathrm{L}$ de sulfato de magnésio heptahidratado. Após diluição, o meio continha um teor de sólidos solúveis de $9,4{ }^{\circ}$ Brix. Os tubos de ensaio foram incubados a $30^{\circ} \mathrm{C}$, por 24 horas em estufa microbiológica.

\section{Estudo cinético}

O meio de fermentação foi constituído pelo mesmo meio utilizado para o pré-inóculo. Após a incubação, os pré-inóculos foram transferidos para erlenmeyers contendo $140 \mathrm{~mL}$ de meio complexo estéril e foram colocados em incubadora com agitação orbital a $30^{\circ} \mathrm{C}$ e $170 \mathrm{rpm}$, em duplicata para cada linhagem. Nas primeiras 10 horas, foram retiradas amostras com volume de $10 \mathrm{~mL}$ de hora em hora (com exceção do tempo de 5 horas) e ao final do estudo cinético, após 25 horas. Logo após a coleta das amostras, elas foram centrifugadas a $1000 \mathrm{~g} / 15 \mathrm{~min}$ e os sobrenadantes foram analisados quanto aos teores de açúcares redutores totais (ART) e os precipitados foram analisados quanto à concentração de massa seca.

\section{Métodos Analíticos}

Massa seca - As amostras coletadas, após centrifugação e separadas do sobrenadante, foram secas em estufa a vácuo a $60^{\circ} \mathrm{C}$ por 24 horas, colocadas em dessecador por 30 minutos e pesadas em balança analítica (ANDRIETTA et al., 1995).

Açúcares redutores totais - Foram determinados usandose método espectrofotométrico a $540 \mathrm{~nm}$, após reação com ácido dinitrosalicílico (DNS) (MILLER, 1959). Antes de serem analisadas, as amostras sofreram hidrólise ácida com solução de $\mathrm{HCl} 2 \mathrm{~N}$.

Cálculo dos fatores de conversão de substrato em biomassa (Yx/s)

Os fatores de conversão de substrato em biomassa foram calculados através da equação 1 :

$$
\mathrm{Yx} / \mathrm{s}=-(\mathrm{Xf}-\mathrm{Xo}) /(\mathrm{Sf}-\mathrm{So})
$$


onde Xf é a concentração celular final (g matéria seca/ L), Xo é a concentração celular inicial (g matéria seca/ L), Sf é a concentração final de açúcares (g ART/ L) e So é concentração inicial de açúcares (g ART/L).

\section{Determinação da velocidade específica máxima de crescimento ( $\mu$ máx)}

As velocidades específicas máximas de crescimento ( $\mu$ máx) foram determinadas através da construção do gráfico Ln X/Xo em função do tempo, obtendo-se o valor de $\mu$ max pelo coeficiente angular da reta ajustada aos dados experimentais na fase exponencial de crescimento, conforme a equação 2 :

$$
\operatorname{Ln}(\mathrm{X} / \mathrm{Xo})=\mu \text { máx. } \mathrm{t} \text {. }
$$

A amostra de Rio Manso apresentou 4 linhagens dominantes, enquanto que no alambique de Betim, foram obtidas três linhagens dominantes para as duas amostras (Tabela 1). Nas amostras de Betim, o padrão morfológico e a ordem de concentração das linhagens isoladas foram coincidentes (Tabela 1 e 2). Os isolados RM01 e CV01 foram selecionados para os testes cinéticos, pela maior concentração observada para essas linhagens.

Foram obtidas as curvas de crescimento para as linhagens RM01 e CV01 (Figura 1). Verificou-se que as linhagens RM01 e CV01 atingiram concentrações, ao final da fermentação, superiores a $10 \mathrm{~g}$ cel.seca/L. A partir dos
Tabela 1 - Concentrações dos isolados de levedura.

\begin{tabular}{ccc}
\hline Amostra & Isolado & $\begin{array}{c}\text { Concentração } \\
(\mathrm{UFC} / \mathrm{mL})\end{array}$ \\
\hline \multirow{3}{*}{ Rio Manso } & RM01 & $2,0 \times 10^{7}$ \\
& $\mathrm{RM02}$ & $2,5 \times 10^{6}$ \\
& $\mathrm{RM} 03$ & $6,5 \times 10^{5}$ \\
& $\mathrm{RM} 04$ & $4,0 \times 10^{5}$ \\
\hline \multirow{3}{*}{ Betim } & $\mathrm{CV} 01 / \mathrm{CV} 04$ & $1,3 \times 10^{8} / 7,0 \times 10^{5}$ \\
& $\mathrm{CV} 02 / \mathrm{CV} 05$ & $1,0 \times 10^{7} / 6,0 \times 10^{4}$ \\
& $\mathrm{CV} 03 / \mathrm{CV} 06$ & $1,0 \times 10^{6} / 2,0 \times 10^{4}$ \\
\hline
\end{tabular}

resultados das curvas de crescimento celular, foram construídos os gráficos $\ln (\mathrm{X} / \mathrm{Xo})$ versus tempo e foram determinados os valores de $\mu$ max a $30^{\circ} \mathrm{C}$, como mostra a Tabela 3.

Na Figura 2, é apresentado o gráfico para determinação de $\mu$ max para a linhagem RM01. Os coeficientes de correlação $\left(\mathrm{R}^{2}\right)$ das regressões lineares foram elevados $(0,95)$, mostrando bom ajuste aos dados experimentais. A linhagem RM01 apresentou o valor mais elevado para a velocidade específica máxima de crescimento $\left(0,4 \mathrm{~h}^{-1}\right)$. Alves (1996) fez uma revisão bibliográfica sobre parâmetros cinéticos e relatou valores de $\mu$ max entre 0,19 e $0,64 \mathrm{~h}^{-1}$ e valores de $\mathrm{Yx} / \mathrm{s}$ entre $0,03 \mathrm{e}$ 0,28 g.g $\mathrm{g}^{-1}$, para Saccharomyces cerevisiae. Alves (1996) e Carvalho et al. (1996) obtiveram valores de $\mu$ max variando entre 0,3 e $0,4 \mathrm{~h}^{-1}$ para linhagem isolada de usina de álcool,

Tabela 2 - Padrão macromorfológico das linhagens selecionadas.

\begin{tabular}{|c|c|c|c|c|c|}
\hline Isolado & $\begin{array}{l}\text { Tamanho } \\
(\mathrm{mm})\end{array}$ & Superfície & Borda & Elevação & Coloração \\
\hline RM01 & $5-7$ & Lisa & Regular & Umbonada* & $\begin{array}{l}\text { Centro verde claro circundado por borda larga } \\
\text { branca }\end{array}$ \\
\hline RM02 & $7-8$ & Rugosa & Irregular & Elevada & $\begin{array}{l}\text { Centro verde claro circundado por borda } \\
\text { branca }\end{array}$ \\
\hline RM03 & 4 & Lisa & Regular & Umbonada* & $\begin{array}{l}\text { Verde escura circundada por borda branca } \\
\text { estreita }\end{array}$ \\
\hline RM04 & 4 & Lisa & Regular & Umbonada* & $\begin{array}{l}\text { Centro verde claro circundado por uma borda } \\
\text { larga de verde mais claro }\end{array}$ \\
\hline CV01/CV04 & $8-10$ & Rugosa & Irregular & Elevada & $\begin{array}{l}\text { Centro verde claro circundado por borda larga } \\
\text { branca ou branca e verde claro }\end{array}$ \\
\hline CV02/CV05 & $7-8$ & Rugosa & Irregular & Elevada & $\begin{array}{l}\text { Centro verde escuro circundado por anel verde } \\
\text { mais claro; borda larga branca }\end{array}$ \\
\hline CV03/CV06 & 6 & Lisa & Regular & Umbonada* & Cor uniforme verde claro \\
\hline
\end{tabular}

* Elevação central. 


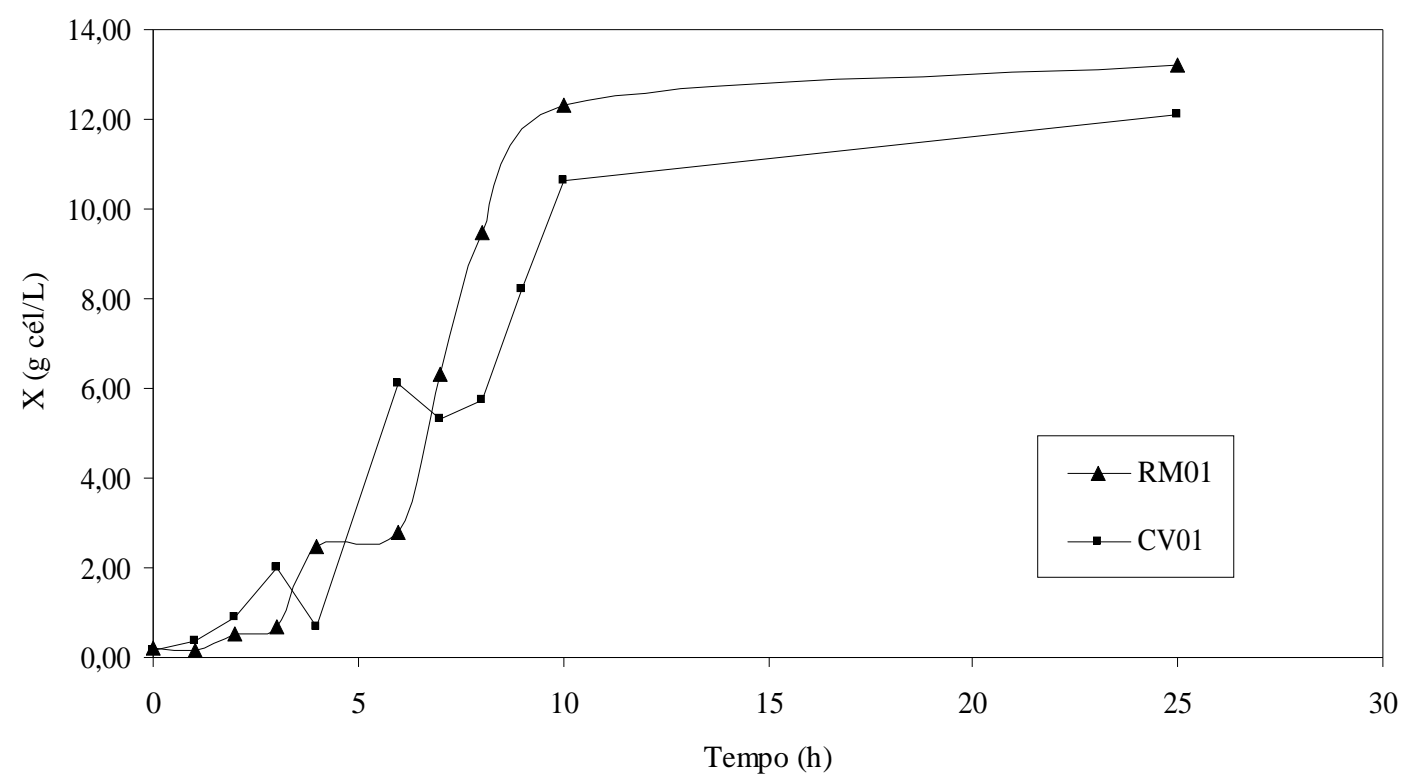

Figura 1 - Curvas de crescimento das duas linhagens dominantes.

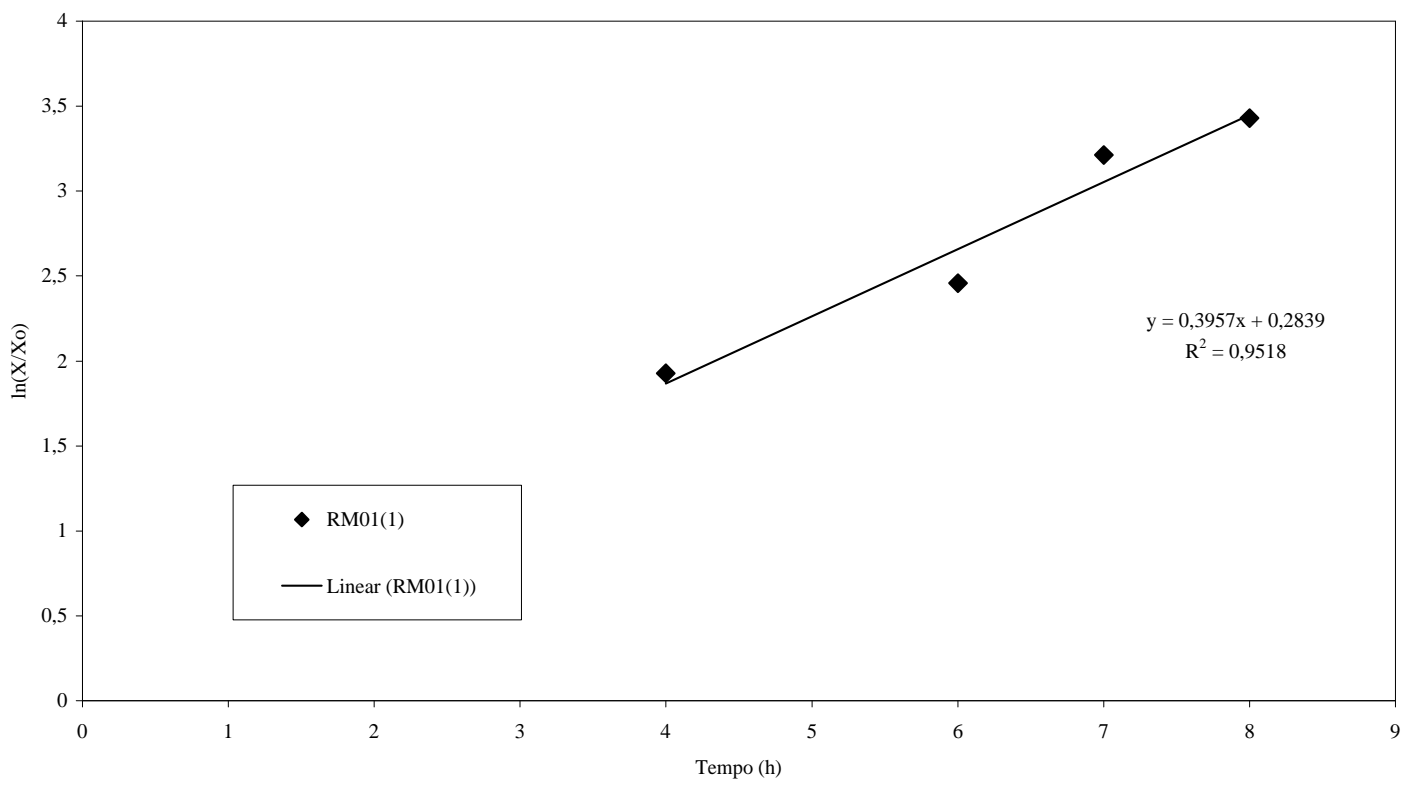

Figura 2 - Gráfico para determinação de $\mu$ max da linhagem RM01 a $30^{\circ} \mathrm{C}$.

na faixa de temperatura de 28 a $38^{\circ} \mathrm{C}$, em processo de fermentação contínua, utilizando meio com melaço de canade-açúcar (40 gART/L) e 2,5 g/L de extrato de levedura. Em outros trabalhos, são encontrados valores similares aos obtidos neste trabalho, como em Jarzebski et al. (1989), que obtiveram um valor de $\mu$ max de $0,24 \mathrm{~h}^{-1}$ e Maiorella et al. (1984), que obtiveram $0,461 \mathrm{~h}^{-1}$, ambos para Saccharomyces cerevisiae, a $30^{\circ} \mathrm{C}$. Stroppa et al. (2000) estudaram a dinâmica populacional em duas usinas de álcool no estado de São Paulo, isolaram várias linhagens e as velocidades específicas máximas de crescimento foram determinadas, situando-se entre 0,27 e $0,57 \mathrm{~h}^{-1}$, utilizando meio sintético $\left(4,0 \%\right.$ de glicose; $1,5 \% \mathrm{KH}_{2} \mathrm{PO}_{4} ; 0,5 \% \mathrm{NH}_{4} \mathrm{Cl}$; $0,1 \% \mathrm{MgSO}_{4} .7 \mathrm{H}_{2} \mathrm{O} ; 0,1 \% \mathrm{KCl} ; 0,6 \%$ extrato de levedura). Oliveira et al. (2004) analisaram as características fermentativas de várias linhagens dominantes de leveduras 
isoladas de alambiques, de destilarias de cachaça industrial e de álcool carburante e obtiveram valores de max entre 0,38 a $0,67 \mathrm{~h}^{-1}$, utilizando meio sintético, com $40 \mathrm{~g} / \mathrm{L}$ de glicose.

Os resultados obtidos para os fatores de conversão de substrato em biomassa das 2 linhagens estudadas foram calculados pela equação 1 e seus valores foram 0,179 e 0,185 g cél. seca/g ART para as linhagens RM01 e CV01, respectivamente (Tabela 3). Oliveira et al. (2004) obtiveram valores para os fatores de conversão de substrato em biomassa na faixa de 0,039 a $0,072 \mathrm{~g} / \mathrm{g}$, utilizando meio sintético, com $150 \mathrm{~g} / \mathrm{L}$ de glicose. Alves (1996) estudou a cinética de crescimento anaeróbico de uma linhagem de Saccharomyces cerevisiae isolada de destilaria de álcool carburante numa faixa de temperatura de 28 a $38^{\circ} \mathrm{C}$ e obteve valores do fator de conversão de substrato em células entre 0,087 e $0,099 \mathrm{~g}$ cél/gART, utilizando meio com melaço de cana-de-açúcar (40 gART/L) e 2,5 g/L de extrato de levedura. Na literatura, são relatados valores de $\mathrm{Yx} / \mathrm{s}$ para microrganismos produtores de etanol numa faixa ampla, de 0,03 a $0,28 \mathrm{~g} / \mathrm{g}$, embora na maioria dos trabalhos o limite máximo situe em torno de $0,1 \mathrm{~g} / \mathrm{g}$ (ANDRIETTA \& STUPIELLO, 1990; DOMÍNGUEZ et al., 1993; JARZEBSKI et al., 1989). Portanto, os valores obtidos nesse trabalho estão relativamente altos. Uma possível explicação para isso seria que os experimentos foram conduzidos em condições ótimas para crescimento celular de leveduras, enquanto que, na maioria dos trabalhos, fermentação alcoólica e crescimento celular ocorriam simultaneamente, em condições otimizadas para fermentação alcoólica.

Tabela 3 - Valores de $\mu$ max e Yx/s para as linhagens RM01 e CV01.

\begin{tabular}{lccc}
\hline Amostra & Isolado & $\begin{array}{c}\mu \max \\
\left(\mathrm{h}^{-1}\right)\end{array}$ & $\begin{array}{c}\text { Yx/s } \\
\text { (g cel.seca/ } \\
\text { g ART })\end{array}$ \\
\hline Rio Manso & RM01 & 0,40 & 0,179 \\
\hline Betim & CV01 & 0,24 & 0,185 \\
\hline
\end{tabular}

Andrietta et al. (1999) desenvolveram metodologia para classificação das linhagens de levedura de processos industriais de fermentação alcoólica, utilizando capacidade fermentativa. Utilizaram seis parâmetros para a definição do grupo de cada linhagem, entre eles, $\mu$ max e Yx/s. Estabeleceram três níveis para cada parâmetro: baixo, médio e alto. Para $\mu$ max, os níveis foram menor que 0,45 (baixo); entre 0,45 e 0,55 (médio) e maior que $0,55 \mathrm{~h}^{-1}$ (alto). Para $\mathrm{Yx} / \mathrm{s}$, os níveis foram menor que 0,041 (baixo); entre 0,041 e 0,044 (médio) e maior que 0,044 g.g $\mathrm{g}^{-1}$ (alto). Oliveira et al. (2004) determinaram características fermentativas de 24 linhagens de Saccharomyces cerevisiae e 6 de outras espécies como Candida apicola, Pichia subpelliculosa $e$ Schizosaccharomyces pombe. Esses parâmetros foram divididos em 4 níveis (baixo a muito alto). Comparando os valores de $\mu$ max com as classificações propostas por Andrietta et al. (1999) e Oliveira et al. (2004), verifica-se que os valores obtidos neste trabalho encontram-se no nível mais baixo (menor que $0,45 \mathrm{~h}^{-1}$ ), enquanto que, com relação ao fator de conversão de substrato em biomassa, verifica-se que os valores obtidos neste trabalho encontram-se no nível alto. Analisando-se os resultados, observou-se que a linhagem que cresce mais rápido é a RM01, apresentando também um bom valor para $\mathrm{Yx} / \mathrm{s}$, que são características desejáveis na etapa de propagação do fermento.

$\mathrm{O}$ pequeno número de linhagens dominantes de leveduras isoladas mostra que, apesar do aporte contínuo de linhagens selvagens ao processo, trazidas pelo caldo ou presentes no ambiente e equipamentos, somente algumas leveduras são mais adaptadas às condições de operação e multiplicam-se na dorna. Estes isolados representam potenciais inóculos para os processos de fermentação comercial.

Os valores obtidos experimentalmente para $\mu \max$ situam-se dentro da faixa de valores encontrados na literatura, sendo que a linhagem RM01 apresentou o valor mais alto $\left(0,4 \mathrm{~h}^{-1}\right)$. Os fatores de conversão de substrato em células obtidos foram relativamente elevados quando comparados aos relatados na literatura (maiores que 0,079 g. $\mathrm{g}^{-1}$ ), possivelmente devido ao uso de condições otimizadas visando, exclusivamente, ao crescimento celular.

Concluiu-se, portanto, que RM01 é a melhor linhagem de levedura em termos de $\mu$ max e Yx/s, dentre as duas estudadas, pois seu crescimento foi mais rápido e apresentou um bom fator de conversão de substrato em células. Entretanto, vários outros parâmetros, como por exemplo, avaliação sensorial, produção de etanol e custos de manutenção desta e de outras linhagens devem ser avaliados para a escolha adequada de uma levedura para produção de cachaça.

\section{REFERÊNCIAS BIBLIOGRÁFICAS}

ALVES, J. G. L. F. Estudo da influência da temperatura na cinética de crescimento anaeróbico de Saccharomyces cerevisiae. 1996. 69 f. Dissertação (Mestrado em Engenharia de Alimentos) - Universidade Estadual de Campinas, Campinas, 1996. 
ANDRIETTA, S. R.; ANDRIETTA, M. G. S.; RODRIGUES, M. I. Método de caracterização de leveduras de processo utilizando parâmetros cinéticos e produção específica. STAB, Açúcar, Álcool e Subprodutos, Piracicaba, v. 13, n. 4, p. 22-25, 1995.

ANDRIETTA, S. R.; SERRA, G. E.; ANDRIETTA, M. G. S. Classificação das linhagens de leveduras de processos industriais de fermentação alcoólica utilizando capacidade fermentativa. STAB, Açúcar, Álcool e Subprodutos, Piracicaba, v. 17, n. 5, p. 54-59, 1999.

ANDRIETTA, S. R.; STUPIELLO, J. P. Simulação e modelagem para processo de fermentação alcoólica (I) batelada alimentada. STAB, Açúcar, Álcool e Subprodutos, Piracicaba, v. 8, p. 36-40, 1990.

BARROS-LOPES, M.; SODEN, A.; HENSCHKE, P. A.; LANGRIDGE, P. PCR differentiation of commercial yeast strains using intron splice site primers. Applied and Environmental Microbiology, Washington, v. 62, p. 45144520, 1996.

CARVALHO, B. S.; ALVES, J. G. L. F.; MAUGERI FILHO, F. Modelagem matemática de fermentação alcoólica em função da temperatura. In: SIMPÓSIO NACIONAL DE FERMENTAÇÕES, 11., 1996, São Carlos. Anais... São Carlos: UFSCar, 1996. v. 2, p. 658-663.

CLETO, F.V.G.; RAVANELI, G.C.; MUTTON, M.J.R. Effects of corn meal and sulphuric acid on the production of cachaça. Ciência e Agrotecnologia, Lavras, v.33, n.5, p. 1379-1384, set./out., 2009.

DOMÍNGUEZ, H.; NÚNEZ, M. J.; CHAMY, R.; LEMA, J. M. Determination of kinetic parameters of fermentation processes by a continuous unsteady-state method: application to the alcoholic fermentation of D-xylose by Pichia stipitis. Biotechnology and Bioengineering, New York, v. 41, p. 1129-1132, 1993.

FLEET, G. H.; LAFON-LAFOURCADE, S.; RIBEREAUGAYON, P. Evolution of yeasts and acid bacteria during fermentation and storage of Bordeaux wines. Applied and Environmental Microbiology, Washington, v. 48, p. 10034-1038, 1984.

JARZEBSKI, A. B.; MALINOWSKI, J. J.; GOMA, G. Modeling of ethanol fermentation at high yeast concentrations. Biotechnology and Bioengineering, New York, v. 34, p. 1225-30, 1989.
LONGO, E.; VELÁZQUEZ, L. B.; SIEIRO, C.; CANSADO, J.; CALO, P.; VILA, T. G. Production of higher alcohols, ethyl acetato, acetaldehyde and other compounds by Saccharomyces cerevisiae wine strains isolated from the same region. World Journal of Microbiology and Biotechnology, Oxford, v. 8, p. 539-541, 1992.

MAIORELLA, B. L.; BLANCH, H. W.; WILKE, C. R. Economic evaluation of alternative ethanol fermentation processes. Biotechnology and Bioengineering, New York, v. 26, p. 1003-1025, 1984.

MILLER, G. L. Use of dinitrosalicylic acid reagent for determination of reducing sugar. Analytical Chemistry, Washington, v. 31, n. 3, p. 426-428, 1959.

OLIVEIRA, E. S.; ROSA, C. A.; MORGANO, M. A.; SERRA, G. E. Fermentation characteristics as criteria for selection of cachaça yeast. World Journal of Microbiology and Biotechnology, Oxford, v. 20, p. 19-24, 2004.

PATARO, C.; GOMES, F. C. O.; ARAÚJO, R. A. C.; ROSA, C. A.; SCHWAN, R. F.; CAMPOS, C. R.; CLARET, A. S.; CASTRO, H. A. Utilização de leveduras selecionadas na fabricação da cachaça de alambique. Informe

Agropecuário, Belo Horizonte, v. 23, n. 217, p. 37-43, 2002.

PATARO, C.; GUERRA, J. B.; PETRILLO-PEIXOTO, M. L.; MENDONÇA-HAGLER, L. C.; LINARDI, V. R.; ROSA, C. A. Yeast communities and genetic polymorphism of Saccharomyces cerevisiae strains associatec with artisanal fermentation in Brazil. Journal of Applied Microbiology, Oxford, v. 89, p. 24-31, 2000.

QUEROL, A.; BARRIO, E.; RAMON, D. A. A comparative study of different methods of yeast strain characterization. Systematic and Applied Microbiology, Stuttgart, v. 15, p. 439-446, 1992.

RIBEIRO, J. C. G. M. Fabricação artesanal da cachaça mineira. Belo Horizonte: O Lutador, 2002. 223 p.

SANNI, A. I.; LONNER, C. Identification of yeasts isolated from Nigerian traditional alcoholic beverages. Food Microbiology, London, v. 10, p. 517-523, 1993.

SCHWAN, R. F.; CASTRO, H. A. Fermentação alcoólica. In: CARDOSO, M. das G. Produção de aguardente de cana-de-açúcar. Lavras: UFLA, 2001. p. 45-57.

STROPPA, C. T.; ANDRIETTA, S. R.; ANDRIETTA, M. G. S. Dinâmica populacional de leveduras em processos de fermentação alcoólica. In: SIMPÓSIO NACIONAL DE FERMENTAÇÕ̃ES, 13., 2000, Teresópolis. Anais.. Teresópolis: [s.n.], 2000. CD-ROM. 